This item was submitted to Loughborough's Research Repository by the author.

Items in Figshare are protected by copyright, with all rights reserved, unless otherwise indicated.

\title{
Brand consistency and coherency at the London 2012 Olympic Games
}

PLEASE CITE THE PUBLISHED VERSION

http://dx.doi.org/10.1080/0965254X.2017.1293139

PUBLISHER

(C) Taylor \& Francis

VERSION

AM (Accepted Manuscript)

\section{PUBLISHER STATEMENT}

This work is made available according to the conditions of the Creative Commons Attribution-NonCommercialNoDerivatives 4.0 International (CC BY-NC-ND 4.0) licence. Full details of this licence are available at: https://creativecommons.org/licenses/by-nc-nd/4.0/

\section{LICENCE}

CC BY-NC-ND 4.0

\section{REPOSITORY RECORD}

Kenyon, James Andrew, Elisavet Manoli, and Guillaume S.P. Bodet. 2019. "Brand Consistency and Coherency at the London 2012 Olympic Games". figshare. https://hdl.handle.net/2134/24044. 


\section{Brand consistency and coherency at the London 2012 Olympic Games}

James Andrew Kenyon ${ }^{1}$, Argyro Elisavet Manoli ${ }^{1}$ \& Guillaume Bodet ${ }^{2}$

${ }^{1}$ School of Sport, Exercise and Health Sciences / Centre for Olympic Studies and Research, Loughborough University

${ }^{2}$ Laboratoire CRIS/L-Vis, Université de Lyon, Université Claude Bernard Lyon-1

Corresponding author: Dr. James Andrew Kenyon, Sport Policy and Management Group (SPMG) / Centre for Olympic Studies and Research (COSR), School of Sport, Exercise and Health Sciences, John Beckwith Building (JB.2.15), Loughborough University, Loughborough, Leicestershire, LE11 3TU | email: J.A.Kenyon@lboro.ac.uk

Version: Accepted, $17^{\text {th }}$ January 2017 


\section{Brand consistency and coherency at the London 2012 Olympic Games}

As brand management and brand perceptions attract more attention in both academia and in practice, examining the link or lack thereof between brand identity and image is becoming increasingly important. The existence of brand consistency and coherency is examined in this research, which aimed to evaluate whether the pre- or post-event brand image of the Olympic Games or the London 2012 Games, in the domestic UK population and media, were aligned with the brand identities of these objects. Online surveys and media content analysis revealed that both brands have yet to achieve consistency or coherency within these two key stakeholder groups, even though the brand image of the 2012 Games improved following the event. What this study suggests is that unless the brand owner takes key stakeholders' perceptions into consideration, a coherent and consistent brand identity does not necessarily equate to these being a feature of the brand image, with the connection between perceptions requiring additional attention.

Keywords: brand coherency; brand consistency; brand identity; brand image; brand perceptions; 2012 Olympic Games

\section{Introduction}

The creation and management of brands has attracted significant attention from both academics and practitioners in the past five decades, with numerous and often contradicting views being expressed. From the company-controlled rigid brand (Keller, 2003), to the consumer-focused flexible personality (Gummersson, 2006; Kitchen, Kim \& Schultz, 2008), branding has transformed within both the academic literature and in practice. Yet, recent studies argue that those on both sides of the spectrum fail to capture the true notion of modern brand management. On the contrary, and in line with the overall increasing appreciation of multiple stakeholders' importance, the recent branding literature points toward multi-stakeholder co-creation and management of brands (Christodoulides, 2009; Pongsakornrungsilp \& Schroeder, 2011). The 
supposition here is that a significant element of a brand is the product of interaction between the brand owner/manager and its stakeholders, such as customers and the media. However, a brand's identity - created and managed by the brand owner/manager - does not always correspond to the brand image as perceived by customers or broadcast by the media. Given that a brand depends on the brand-related interaction of these different stakeholders, this can, in fact, lead to inconsistent results (Hatch \& Schultz, 2003).

With the wider audience that brands now have access to, caused by the proliferation of traditional and digital media, and the gradual power shift in communications from organisations to stakeholders, the need to reduce the polyphony of perceptions that might exist around a brand has become increasingly important. 'Misperceptions’ or perception gaps are these image inconsistencies that might exist among different stakeholder groups, which have been identified as critical impediments in a brand's success (Harris, \& de Chernatony, 2001). In fact, narrowing the gap between brand identity and brand image has been linked with the financial value of a brand since the 1980s (de Chernatony, 1999). What could then be argued is that the creation and maintenance of a strong brand identity-image link could result in a coherent and consistent brand. This in turn raises the question of brand consistency, of which the literature remains in relative adolescence within academia. The assumption here is that if consistency and coherency are achieved, this can have a direct impact upon an organisation's communications campaign effectiveness and the brand's marketbased and financial performance (Luxton, Reid \& Mavondo, 2015). Yet, despite the perceived importance of such an achievement, there have been relatively few studies that have sought to determine whether brand consistency is ever in fact realised. With that in mind then, the aim of this study was to investigate the brand consistency of 'the 
sports world's most powerful brand', the Olympic brand (Seguin \& O’Reilly, 2008, p.62), and that of the specific London 2012 iteration.

\section{Theoretical background}

\section{Brand identity-image link}

According to Burmann and colleagues, the literature and research related to brands focuses on understanding the concept from one of two perspectives: either, 'the brand as perceived by the purchaser, i.e. the 'outside-in perspective' [...]. [Or] the brand as constructed and managed by the owner/manager of the brand, i.e. 'the inside-out perspective' (Burmann, Hegner \& Riley, 2009, p.114). Dealing first then with the latter 'inside-out' perspective, this is more commonly referred to as brand identity. It describes the processes by which brand owners and managers endeavour to convey the individuality and distinctiveness of their organisations and products (Nandan, 2005, p.265) which includes both visual (tangible) components, such as a name, a logo, a theme, etc., and the brand's social and psychological (intangible) components. These latter components, according to de Chernatony (1999) and Harris and de Chernatony (2001), include: brand vision, brand culture, positioning, personality, relationship, and presentation, the establishment of which serves specific purposes. Primarily, it acts as a set of associations decided by the brand owner/manager to represent a vision of how the brand should be perceived. Once these components are established, a relationship can then be formed between the brand and its target audience, creating value for the latter through benefits or credibility (Konecnik \& Go, 2007).

Conversely, the 'outside-in perspective' denotes, and is more commonly regarded as brand image. Bodet and colleagues define it as 'the characteristics or attributes through which customers evaluate the brand and compare it to others' (Bodet, 
Meurgey \& Lacassagne, 2009, p.371). Quite simply, brand image is the total impression of an organisation, product or place in consumers' minds (Aaker, 1991) which is generated from numerous sources (Herzog, 1963). Brand image is also a dimension within the wider encompassing concept of brand equity. Brand equity has been described as 'a set of brand assets and liabilities linked to a brand, its name and symbol, that add to or subtract from the value provided by a product or service to a firm and/or to that firm's customers' (Aaker, 1991, p.15). Thus, it is considered 'the 'added value' endowed to a product [or organisation] in the thoughts, words, and actions of consumers' (Keller, 2006, p.546). As well as brand image, brand equity also includes the dimensions: perceived quality, brand loyalty, brand awareness and other proprietary assets (Aaker, 1996). At their simplest, 'all of these types of information can be thought of in terms of a set of associations to the brand in consumer memory' (Keller, 2006, p.547); associations which allow the consumer to quickly form an opinion about a brand 'without having to analyse all of the [its] characteristics' (Lebrun, Souchet \& Bouchet, 2013, p.361).

Brand identity and brand image are related concepts, and are both essential components of a strong brand (Nandan, 2005; Srivastava, 2011). However, brand identity should precede brand image insomuch that an organisation must identify what it is that they want to communicate to the consumer (Kapferer, 2008) in order to engender a favourable brand image. Accordingly, the creation and maintenance of a strong identity-image linkage is considered essential (Srivastava, 2011). Before the emergence of the 'stakeholder brand co-creation era' (Vallaster \& Wallpach, 2013, p.1506), the brand owner/manager was considered to be solely in control of a brand, that was created and then unilaterally communicated to the customer, who then behaved as the brand owner/manager intended them to; that is, customers would passively accept and adopt 
the brand identity suggested, and would consequently embrace a brand image to match it (Kotler, 2000; Keller, 2003). As understanding progressed, and an appreciation for the power of the consumer developed, a more customer-focused brand management approach emerged (Gummesson, 2006; Kitchen et al., 2008). Soon, additional stakeholders also began to attract academic attention (Balmer \& Gray, 2003; Chun \& Davies, 2006), much of which was focussed on employees due to their 'brand ambassador’ roles within organisations (Rafiq \& Ahmed, 2000; Schultz \& de Chernatony, 2002). Yet despite these developments, the focus of the literature has remained on the management of the brand and particularly on how the brand owner's/manager's actions should be designed and planned, whereas the brand image of customers, the media, the community, and other stakeholders has yet to be fully explored.

Although there are a few studies concerned with brand meaning co-creation within the literature, its examination has mainly been conducted from particular, specific perspectives; such as, post-modernism in customer behaviour (see Belk \& Costa, 1998; Christodoulides, 2009), brand culture and communities among customers (see Brown, Kozinets, \& Sherry, 2003; Ouwersloot, \& Odekerken-Schröder, 2008), and on-line consumer empowerment (see Prahalad, \& Ramaswamy, 2004; Pongsakornrungsilp, \& Schroeder, 2011). Within this literature, however, brand consistency is investigated somewhat nebulously, with limited attempts made to examine it in practice. Consequently, even if the notion of a less powerful brand owner/manager is accepted within the branding literature, these individuals and their practices are still the focal point of much of the research (Reid et al., 2002; 2003; Luxton, Reid, \& Mavondo, 2015). Thus, the potential gap between brand identity and brand image has yet to be fully explored, even though its importance has been widely 
recognised. Of the limited studies that have focused on brand consistency - that is, investigating the gap between brand identity and brand image - these have mostly looked at the managerial practices behind it (see de Chernatony, 1999; Harris, \& de Chernatony, 2001; Hatch, \& Schultz, 2003), and its connection with globalisation and the international consumer (see Matthiesen \& Phau, 2005; Bengtsson et al., 2010). With that in mind then, the effects of stakeholder interrelations, and the influence that one can have on another, on the existence, or lack thereof, of brand consistency and/or coherency has yet to be captured within the branding literature. This study, therefore, will aim to explore this influence through the examination of brand consistency and coherency within the Olympic brand, which is often referred to as the strongest sports brand in the world (Seguin \& O’Reilly, 2008). Specifically, this study will focus on the London 2012 Olympic Games brand identity, and that of the wider Olympic Games, the domestic UK populations' brand image of these two entities, and the national media's perception of the Games’ brand, in an attempt to examine whether brand consistency was achieved prior to or following the event. Before the methods of this study are presented, however, the brand identity of the Olympic Games and the London 2012 Summer Olympic Games will first be presented.

\section{Branding the Olympic Games}

Central to the modern day Olympic Games’ brand is the historic and widely-known Olympic Rings emblem, described by its designer, de Coubertin, as: ‘five interlaced rings [...]: blue, yellow, black, green and red [...]. This design is symbolic; it represents the five continents of the world, united by Olympism’ (de Coubertin, 1931, p.470). Since its conception the symbol has been widely communicated (through the Olympic Games, and its partners and stakeholders) and is now recognised as one of the most recognised global brands; a brand that 'evoke[s] strong emotional connections with 
people throughout the world’ (Ferrand, Chappelet \& Séguin, 2012, p.55). With that in mind then, in the mid-1980s the IOC began attempting to better understand these 'strong emotional connections' in the form of market research that aimed to establish the attitudes towards, and perceptions of the Olympics in the general public (Maguire, Barnard, Butler et al., 2008); a development which, by the late 1990s, led to 'a greater emphasis on the utilization of [such] attitudes and perceptions in order to develop the Olympic brand' (ibid, p.67). As a result of this research (e.g. IOC, 1999), the IOC adopted a strategic approach to the Olympics’ brand management (a programme entitled 'Celebrate Humanity’), one which expressed the core values of the Olympic Games underpinning philosophy (i.e., Olympism) as its foundation (Séguin et al., 2008), and one which set out to make the Olympic brand as attractive as possible to potential sponsors and audiences (Maguire et al., 2008); basically, a brand which 'differentiates the Olympic system from other professional sport systems, which in turn gives the brand an attractive position that is supported by strong associations' (Ferrand et al., 2012, p.55). So, what specifically are these 'strong associations' that the IOC is aiming to generate around the Olympics’ brand?

Following the launch of the 'Celebrate Humanity' programme, and published in the Marketing Report of the 2000 Sydney Olympic Games, the IOC initially saw the Olympic brand as being comprised of four ‘complimentary messages’ (IOC, 2001, p.30):

(1) Hope

(2) Dreams \& Inspiration

(3) Friendship \& Fair Play

(4) Joy in the Effort 
With each successive Olympic Games following the 2000 event the 'Celebrate Humanity’ programme was updated and revised such that by the time of 2006 Torino Winter Games, the way in which the Olympic brand identity was conceived by the IOC had become what it is today, and instead of four 'complimentary messages', it now consists of three Olympic values, Excellence, Friendship and Respect, 'which are paired with the five working principles of Olympism: universality, solidarity, collaboration, autonomy and social responsibility’ (IOC, 2012, p.134; see also, IOC, 2006).

Each Winter and Summer Olympic event tends to build their own separate brand which is informed by the main Olympic Games brand, but which also incorporates idiosyncratic elements that better represent the brand identity intended by the local organising committee. Consequently, the London 2012 Summer Olympic Games created their own separate brand identity for the event which is examined below.

\section{Branding the 2012 Summer Olympic Games}

There were two main themes running through the image and branding of the 2012 Summer Olympic Games that event stakeholders (e.g. LOCOG) were attempting to create around the London event: inspiration and inclusivity. In the case of the former, this is best exemplified by 2012’s Olympic motto, 'Inspire a Generation’, which emphasised one of the key legacy aims of the 2012 Games: to inspire the UK population, and particularly young people, to become more physically active (e.g. DCMS, 2010). In the case of the latter, the ambition of LOCOG is 'to create a Games for everyone, where everyone is invited to take part, join in and enjoy the most exciting event in the world' (LOCOG, n.d. cited in Ferrand et al., 2012, p.152). This is a view mirrored by the DCMS (2008), who emphasised that the London 2012 Games were building a legacy of inclusivity and thus were open to diverse communities and people. With that in mind then, LOCOG developed a brand that both reflects this focus on the 
2012 Games being the most ‘accessible and participative' Olympics ever staged (Ferrand et al., 2012, p.152), while at the same time, 'reflect[ing] the strengths of the existing London and Britain brands, [...] [and remaining] appropriate to the wider Olympic and Paralympic brand values and imagery’ (DCMS, 2006, p.17). Launched in 2007, the London 2012 brand is centred on the Games’ official logo, which represents simplicity, boldness, energy and youth in spirit (LOCOG, 2011 cited in Ferrand et al., 2012). In this regard, the brand was designed 'to appeal particularly to young people' (IOC, 2012, p.137) which in addition to affirming LOCOG's commitment to the 2012 Games' legacy, can be regarded, at least in part, as a response to what is described by Milton-Smith (2002, p.132) as the 'disillusionment' with the Olympics Games that is 'particularly strong among the younger generation'. According to then-IOC President Jacques Rogge the London 2012 brand was: '[...] an early indication of the dynamism, modernity and inclusiveness with which London 2012 will leave its Olympic mark' (Rogge, 2007 cited in IOC, 2010, p.8)

\section{Methods}

\section{Domestic population}

To collect data from the UK population, an online survey was conducted using the Bristol Online Surveys service ${ }^{1}$. The main element of this survey consisted of free word-association tasks aimed at determining the population's perceptions and attitudes toward the Olympic Games and the 2012 event; that is, their "relatively unrestricted [...] mental representations” (Meliou \& Maroudis, 2010, p.118). Free word-association is considered a particularly useful method for investigating brand image (see for example, Spears, Brown, \& Dacin, 2006; Bodet et al., 2009; Lebrun, Souchet \& Bouchet, 2013). When compared to other relevant qualitative methods, such as story- 
telling and the use of collages, Koll, Wallpach \& Kreuzer (2010) maintain that although free word-association elicits fewer and less unique 'knowledge elements' of a brand, it is quicker to uncover the most frequently cited elements. This is particularly useful in the context of this study insomuch that, referring to research conducted by Dancin \& Brown (2006), the authors argue that brand managers are, in fact, far more concerned with 'brand knowledge that is frequent than brand knowledge that is rare' (Koll et al., 2010, p.593) - which is what the authors were aiming to establish. For this study then, both before and after the 2012 event took place, participants were requested, as British citizens $^{2}$, to provide spontaneous associative responses to the inductors: ‘the Olympic Games’ and ‘the London 2012 Summer Olympic Games’: e.g. As a British citizen, what are the first 10 words that come to mind when you hear 'the Olympic Games'? Participants were asked to provide ten responses, but were advised that seven would be sufficient provided they had thought about the inductor term thoroughly and 'had mentally manipulated it from different perspectives, representing different social views (i.e., what kind of words other people could associate to the object)' (Bodet \& Lacassagne, 2012, p.365). The remainder of the online survey contained items designed to ascertain the demographic profile of participants.

With the London 2012 Olympic Games held between 27th July and 12th August 2012, data was collected, pre-event, between the 1st September 2011 and 31st December 2011 (approx. 11 to eight months prior to the start of the event), and, postevent, between the 12th February 2013 and 12th May 2013 (exactly six-to-nine months after). Participants, both pre- and post-event, were recruited using a combination of convenience sampling and exponential non-discriminative snowball sampling. To ensure as large a sample size as possible, the only limiting criteria were that participants 
Table 1. Descriptive Statistics

Age

\begin{tabular}{ccccc} 
mean & 29.9 & \pm 13.9 & 29.8 & \pm 13.7 \\
& $\mathrm{n}$ & $\%$ & $\mathrm{n}$ & $\%$ \\
\cline { 2 - 5 } $18-24$ & 340 & 60.6 & 64 & 29.8 \\
$25-34$ & 77 & 13.7 & 86 & 40.0 \\
$35-44$ & 27 & 4.8 & 15 & 7.0 \\
$45-54$ & 80 & 14.3 & 31 & 14.4 \\
$55-64$ & 27 & 4.8 & 15 & 7.0 \\
$65+$ & 10 & 1.8 & 4 & 1.8
\end{tabular}

Gender

\begin{tabular}{ccccc} 
& $\mathrm{n}$ & $\%$ & $\mathrm{n}$ & $\%$ \\
\cline { 2 - 5 } Female & 325 & 57.9 & 114 & 53.0 \\
Male & 236 & 42.1 & 101 & 47.0
\end{tabular}

Geographic Location

$$
\begin{array}{r}
\text { East Midlands } \\
\text { East of England } \\
\text { Greater London } \\
\text { Isle of Man } \\
\text { North East England } \\
\text { North West England } \\
\text { Northern Ireland } \\
\text { Scotland } \\
\text { South East England } \\
\text { South West England } \\
\text { Wales } \\
\text { West Midlands }
\end{array}
$$

Yorkshire and the Humber
Pre

Post

\begin{tabular}{cccc}
$\mathrm{n}$ & $\%$ & $\mathrm{n}$ & $\%$ \\
\hline 70 & 12.5 & 25 & 11.6 \\
38 & 6.8 & 15 & 7.0 \\
47 & 8.4 & 23 & 10.7 \\
1 & 0.2 & 1 & 0.5 \\
7 & 1.2 & 3 & 1.4 \\
114 & 20.3 & 60 & 27.9 \\
1 & 0.2 & 2 & 0.9 \\
2 & 0.4 & 8 & 3.7 \\
138 & 24.6 & 28 & 13.0 \\
60 & 10.7 & 14 & 6.5 \\
15 & 2.7 & 3 & 1.4 \\
41 & 7.3 & 17 & 7.9 \\
27 & 4.8 & 16 & 7.4
\end{tabular}

Employment

Full-Time Student Other

Retired

Self-Employed Unable to Work

Unemployed Voluntary

Working Full Time Working Part Time Would Rather Not State

\begin{tabular}{cccc}
\multicolumn{2}{c}{ Pre } & \multicolumn{2}{c}{ Post } \\
$\mathrm{n}$ & $\%$ & $\mathrm{n}$ & $\%$ \\
\hline 270 & 48.1 & 56 & 26.0 \\
4 & 0.7 & 3 & 1.4 \\
12 & 2.1 & 5 & 2.3 \\
1 & 0.2 & 0 & 0.0 \\
1 & 0.2 & 0 & 0.0 \\
20 & 3.6 & 5 & 2.3 \\
2 & 0.4 & 1 & 0.5 \\
195 & 34.8 & 130 & 60.5 \\
50 & 8.9 & 14 & 6.5 \\
6 & 1.1 & 1 & 0.5
\end{tabular}

\section{Ethnicity}

Any Other Asian Background

Any Other White Background

Bangladesh

Black African

Black Caribbean

Chinese

Indian

Mixed Other

Mixed White \& Asian

Mixed White \& Black Caribbean

$$
\text { White }
$$

\begin{tabular}{cccc}
$\mathrm{n}$ & $\%$ & $\mathrm{n}$ & $\%$ \\
\hline 1 & 0.2 & 1 & 0.5 \\
14 & 2.5 & 3 & 1.4 \\
1 & 0.2 & 0 & 0.0 \\
4 & 0.7 & 3 & 1.4 \\
3 & 0.5 & 1 & 0.5 \\
5 & 0.9 & 0 & 0.0 \\
8 & 1.4 & 0 & 0.0 \\
1 & 0.2 & 0 & 0.0 \\
3 & 0.5 & 1 & 0.5 \\
4 & 0.7 & 0 & 0.0 \\
517 & 92.2 & 206 & 95.8
\end{tabular}

Watching 2012 on TV

\begin{tabular}{rcccc} 
& $\mathrm{n}$ & $\%$ & $\mathrm{n}$ & $\%$ \\
\cline { 2 - 5 } $0-30$ mins & 125 & 22.3 & 29 & 13.5 \\
30mins -1 hour & 139 & 24.8 & 27 & 12.6 \\
1 hour $-11 / 2$ hours & 94 & 16.8 & 36 & 16.7 \\
$1 \frac{1}{1}$ hours -2 hours & 74 & 13.2 & 31 & 14.4 \\
2 hours $-21 / 2$ hours & 40 & 7.1 & 21 & 9.8 \\
$21 / 2$ hours + & 89 & 15.9 & 71 & 33.0
\end{tabular}


resided in the UK, that they were British citizens (i.e., that they held a UK passport), and that they were over 18 years of age. The demographic profiles of pre- and postevent samples are presented in Table 1.

The individual responses from participants' free word association tasks took the form of either a single word or a very short statement (usually containing two or three words). This data was coded using content analysis procedures in which the responses provided were categorised into different themes. In the initial part of the analysis, specific themes relating to both the Olympic Games and the 2012 event were established by the first and third authors, with the participants' individual responses then placed therein. In the next stage, two senior academics (experts in the field of sport management), established whether the themes were well-reasoned and the terms in them appropriately placed. For the responses that could not be grouped into themes - through, for example, there being no suitable theme -, these were still included in the analysis, but they remained in the data set as unique terms. For the most part, the themes generated gathered together either cognitive (i.e., awareness of and associations with the Olympic Games and the 2012 event) or attitudinal responses (i.e., feelings and emotions toward them). For both inductors (i.e., the Olympic Games and the 2012 event) the three most commonly cited themes were identified which were then used to represent their respective brand images.

\section{National broadsheet media}

In addition to the analysis of the UK population, a media content analysis was conducted on domestic broadsheet media; specifically, The Guardian, The Times, The Independent, the Daily Telegraph, and the BBC’s online outlet. As McNamara (2005) argues, this systematic method of analysing written media allows for the perceptions and interpretations of the media to be identified and understood. This group of 
broadsheet media was selected as it represents a range of 'quality' UK news outlets (see European Journalism Centre, n.d.) located on various positions of the political spectrum, from left-of-centre to right-of-centre. The inclusion of the BBC News website was due to the corporation's role as the UK's official Olympic Broadcaster, and it being the world's largest broadcast news organisation. A LexisNexis ${ }^{\circledR}$ search of these sources was conducted using the terms: ‘Olympic Games’ AND/OR ‘London 2012 Olympic Games', and only articles written between the 1st September 2011 and 31st December 2011, and 12th February 2013 and 12th May 2013 were included in the results (corresponding to the pre- and post-event data collection periods of the domestic population). A thematic analysis was conducted on the search results in which the articles collected were categorised into the same themes drawn from the domestic population's data. Again, the three most common themes were identified which were then used to represent the media's brand image.

\section{Results}

\section{Domestic population brand image}

Dealing first with the main Olympic Games brand image, from the free wordassociation tasks contained in the survey a total of 5246 words/terms were collected from the 561 pre-event respondents, with a mean of 9.4 per person. Thematic analysis produced 189 categories and unique terms. The three most cited themes were all cognitive groupings of terms: 'sport' (cited by $54.4 \%$ of the pre-event respondents), ‘medals / prizes' (49.6\%) and 'athletics’ (48.5\%). Post-event, a total of 1928 citations were collected from the 215 participants, with a mean of 9.0 words per person. Thematic analysis in this instance produced 147 categories and unique terms. Interestingly, the same three cognitive themes as the pre-event analysis were present in 
the post-event findings: 'sport' (cited by 58.6\% of respondents), 'medals / prizes' (57.2\%), and 'athletics' (45.6\%)

For the 2012 London Olympic Games, a total of 4994 citations were collected from the 561 pre-event participants, with a mean of 8.9 words per person. Thematic analysis in this instance produced 298 semantic categories and unique terms. The most frequently cited term in this brand image was 'Olympic venues' (cited by $30.8 \%$ of respondents), a descriptive, cognitive theme that gathers the 2012 Games’ references to accommodation, training facilities and event venues, both generic (e.g., 'arena/s' and ‘stadium/stadia’) and specific (e.g., ‘Eton Dorney’, ‘Lea Valley’ and ‘Quainton Stud'). The next most cited term was 'cost - expensive' (30.5\%), an attitudinal theme that gathers together such negatively-oriented responses as 'costly', 'expensive' and 'overpriced'. Finally, the third most cited term was another cognitive grouping of terms relating to 'tourism/travel' (30.3\%). Post-event, 2024 citations were collected from the 215 participants, with a mean of 9.4 words per person. In this instance, 206 semantic categories and unique terms were produced, and there was a decidedly more positive feel the post-event brand image. The most frequently cited theme was 'medals / prizes', a cognitive theme cited by $44.7 \%$ of respondents. The most likely explanation for this finding relates to Team GB’s performance at the 2012 Games: with a medal haul of 65 medals, 29 of which were gold, far exceeding UK Sport's target of at least 48 medals in total (e.g., UK Sport, 2013, p.28). The next most frequently cited theme was 'enjoyable’, an attitudinal grouping of terms cited by $42.8 \%$ respondents. This is a theme which contained positive adjectives, such as 'amazing', 'fantastic', 'remarkable' and 'wonderful', describing how respondents perceived the 2012 event. Finally, another positive attitudinal theme, 'national pride', was the third most frequently cited (40.5\%), with its occurrence most likely linked to the presence of the two most cited themes. 


\section{National broadsheet media brand image}

Pre-event, a media content analysis of The Guardian, The Times, The Independent, the Daily Telegraph, and the BBC’s online outlet, conducted on stories published between the 1st September 2011 and 31st December 2011, using the aforementioned search terms, produced 1424 relevant articles. Of these the three most common themes of these articles related to 'Olympic athletes - Team GB', 'cheating / doping' and 'Olympic athletes - other countries'. In the post-event data collection period, interest in the Olympic Games and the 2012 event waned significantly compared to the pre-event period, with only 119 stories published between 12th February 2013 and 12th May 2013. Similar to the pre-event results, the most common theme of these articles related to the performance of 'Olympic athletes - Team GB'. The next most common theme related to the Olympics' 'ceremonies', whether that be the opening or closing ceremonies of the event, or even the podium ceremonies in which athletes were awarded their medals. Finally, negatively-oriented stories concerning 'Olympic athletes - other countries' formed the third most-common theme in the post-event analysis. It is worth noting however that the presence of this theme was due to the fact that exOlympic athlete Oscar Pistorius had shot and killed his partner, Reeva Steenkamp, two days after the post-event data collection period began. Thus, the majority of Olympicrelated news following this event (according to the search terms) related its coverage and aftermath.

\section{Discussion}

Through the examination of the results presented above, a number of points can be raised regarding the brands of both the overall Olympic Games and the London 2012 event. 
First, although the brand identities promoted by the IOC (the Olympic Games) and LOGOC (the 2012 event) remained consistent and coherent pre-to-post-event, the domestic population and the media's perceptions neither matched these brand identities nor were consistent throughout (except in the case of the population's brand image of the Olympic Games). In terms of brand coherency, regarding the Olympic Games overall, not one of the brand values (excellence, friendship and respect) or working principles of Olympism (universality, solidarity, collaboration, autonomy and social responsibility) were present in the brand images recorded. Similarly, in the case of the London 2012 event, neither of the main branding themes, inspiration and inclusivity, were present. In terms of brand consistency, although the Olympic Games brand image is not coherent with its brand identity, in the domestic population, consistency was, in fact, achieved (i.e., sport, medals, and athletics appear in both sets of findings). It is perhaps worth noting also that the brand image revealed by this research supports the work of Bodet and Lacassagne (2012) who, in their evaluation of the of the 2008 event, found that neither the Olympics' brand values nor the working principles of Olympism were central features of the Olympic Games’ brand image; in fact, aside from direct references to the London 2012 event, the same three themes featured as the most commonly recorded responses (i.e., sport, medals, and athletics).

Main Olympics aside, the population’s brand image of the 2012 Games experienced significant change pre-to-post-event, with more positive themes present, and a shift in the overall make-up of the brand image from a largely cognitive one to a largely attitudinal image; that is, it contained a higher proportion of themes relating to people's feelings and emotions. This finding supports the Olympic-legacy-oriented work of Karadakis and colleagues who, in their research on resident perceptions of the 2010 Vancouver Games, found that psychological perceptions of the event increased as 
time progresses (Karadakis, Kaplanidou, \& Karlis, 2016). Despite this finding, and returning to the focus of this study, brand consistency of the London 2012 event was, nevertheless, lacking. However, there does seem to exist some positive correlation between the brand image presented by the post-event media and the one expressed by the domestic population (relating to Team GB athletes) supporting Li and Kaplanidou's (2013) work on the 2008 event.

Taking all the above into consideration the present study leaves little room for suggesting that the brand identity of the London 2012 Games and the Olympics overall was positively accepted and adopted. On the contrary, wide perception gaps exist for both entities between the brand identity and image both pre- and post-event. In line with the growing appreciation of brand co-creation by the brand owner/manager and its respective stakeholders, it could be argued that an effort to capture and embrace this was not made in these Olympic Games. Quite the contrary, the brand owners/managers of the two brands (IOC and LOGOC) appeared to maintain the rather outdated view expressed by the earlier branding literature (see Keller 2003) which places them solely in control of the brands, while myopically failing to capture the image and perceptions their brands evoked to key stakeholder groups, such as the domestic fans and the media.

Overlooking the true image of their brand is something the IOC has been criticised for in the past, with particular emphasis focussed on the 'Celebrate Humanity' programme (Maguire et al., 2008). As Maguire and colleagues (2008, p.65) argue, the programme was 'an exercise in enhancing brand equity - for the benefit of the IOC and TOP sponsors', and was conducted using a rather questionable method ('allocating strength of agreement to predefined statements’ [ibid, p.68]), which left no room for negative or contradictory responses. As a result, it could be suggested that the understanding the organisation has of their own brand image is based on non- 
representative data, which can further hinder any efforts to achieve brand consistency, thus underlining the need for this and future studies on the matter.

\section{Conclusion}

This study set out to explore the presence of brand consistency and coherency in the Olympic brand, and in that of the London 2012 Games, prior to and following the event. In doing so the authors sought to compare the brand identity of these two entities with the brand images generated by the domestic UK population and broadsheet press. While recent studies on the matter suggest that a strong, coherent and consistent brand can lead to an organisation's communications campaign effectiveness and the brand's marketbased and financial performance (Luxton, Reid \& Mavondo, 2015), the inconsistencies noted in this study for both the London 2012 Games’ and the overall Olympics’ brand, suggests that there is still ample room for improvement, especially in terms of the latter. In terms of practice, the findings of this research complement those of Karadakis et al. (2016, p.207), who suggest that 'event managers concerned with planning for legacies should focus on maximizing the psychological aspects'. In the context of this study, such a recommendation might also be beneficial to those responsible for managing or developing an event's brand identity, which might go some way to achieving that sought-after consistency and coherency. Despite its contributions, however, it is worth highlighting that this research is, very much, exploratory in nature and should therefore be considered in this context. But with the literature base pertaining to brand consistency and coherency in relative adolescence, the authors have aimed to provide a starting point for future work in the area.

Acknowledgements: The authors would like to thank Professors Paul Downward, Ian Henry, Barrie Houlihan, and Benoit Séguin, for their invaluable expertise and feedback. 


\section{Refer to https://www.onlinesurveys.ac.uk/about/}

2. The inclusion of the phrase 'British citizen' was designed to activate the mental connection between the respondents and their social identity (i.e., British people) ensuring that it was this particular social group that was tapped into.

\section{References:}

Aaker, D. A. (1991). Managing Brand Equity: Capitalizing on the Value of a Brand Name. New York: The Free Press.

Aaker, D. A. (1996). Building Strong Brands. New York: The Free Press.

Balmer, J. M. T., \& Gray, E. R. (2003). Corporate brands: What are they? What of them?. European Journal of Marketing, 37(7/8), 972-997.

Belk, R. W., \& Costa, J. (1998). The mountain man myth: A contemporary consuming fantasy. Journal of Consumer Research, 25(3), 218-240.

Bengtsson, A., Bardhi, F., \& Venkatraman, M. (2010). How global brands travel with consumers: An examination of the relationship between brand consistency and meaning across national boundaries. International Marketing Review, 27(5), 519-540.

Bodet, G., \& Lacassagne, M.-F. (2012). International place branding through sporting events: a British perspective of the 2008 Beijing Olympics. European Sport Management Quarterly, 12(4), 357-374.

Bodet, G., Meurgey, B., \& Lacassagne, M.-F. (2009). Brand social representations: Strategic perspectives for a fitness club. International Journal of Sport Management and Marketing, 5(4), 369-383.

Brown, S., Kozinets, R., \& Sherry, J. F., Jr. (2003). Teaching old brands new tricks: Retro branding and the revival of brand meaning. Journal of Marketing, 67(3), 19-33. Burmann, C., Hegner, S., \& Riley, N. (2009). Towards an identity-based branding. Marketing Theory, 9(1), 113-118. 
Chernatony, L. de (1999). Brand management through narrowing the gap between brand identity and brand reputation. Journal of Marketing Management, 15(1-3), 157179.

Christodoulides, G. (2009). Branding in the post-internet era. Marketing Theory, 9(1), 141-144.

Coubertin, p.de (1931). Textes Choisis. Tome II. Zurich: Hildesheim.

Chun, R., \& Davies, G. (2006). The influence of corporate character on customers and employees: Exploring similarities and differences. Journal of the Academy of Marketing Science, 34(2), 138-146.

Department for Culture, Media and Sport. (2008). Before, During and After: Making the Most of the London 2012 Games. London: Department for Culture, Media and Sport.

Department for Culture, Media and Sport (2010). Plans for the Legacy from the 2012 Olympic and Paralympic Games. London: Department for Culture, Media and Sport. European Journalism Centre (n.d.). Media Landscapes: United Kingdom. Retrieved from: http://ejc.net/media_landscapes/united-kingdom

Ferrand, A., Chappelet, J.-L., \& Séguin, B. (2012). Olympic Marketing. Oxon: Routledge

Gummesson, E. (2006). Many-to-many marketing as grand theory. In, R. F. Lusch, \& S. L. Vargo (eds.) The Service-Dominant Logic of Marketing (pp.339-353). New York: M.E. Sharpe.

Harris, F., \& Chernatony, L. de (2001). Corporate branding and corporate brand performance. European Journal of Marketing, 35(3/4), 441-456.

Hatch, M., \& Schultz, M. (2003). Bringing the corporation into corporate branding. European Journal of Marketing, 37(7/8), 1041-1064. 
Herzog, H. (1963). Behavioral science concepts for analyzing the consumer. In, p.Bliss (ed.) Marketing and the Behavioral Sciences (pp.76-86). Boston: Allyn and Bacon. International Olympic Committee (1999). Global Olympic Research Survey. Olympic Marketing Matters, 15, 9-12.

International Olympic Committee (2001). Sydney 2000 Marketing Report. Lausanne: Meridian Management SA for the International Olympic Committee.

International Olympic Committee (2006). Marketing Report - Torino 2006. Lausanne: International Olympic Committee.

International Olympic Committee. (2010). IOC Marketing: Media Guide. London 2012. Lausanne: International Olympic Committee.

International Olympic Committee. (2012). Marketing Report - London 2012. Lausanne: International Olympic Committee.

Kapferer, J. N. (2008). The New Strategic Brand Management: Creating and Sustaining Brand Equity Long Term. London: Kogan Page.

Karadakis, K., Kaplanidou, K., \& Karlis, G. (2016). Host and non-host resident awareness and perceptions of legacies for the 2010 Vancouver Winter Olympic Games. Loisir et Société / Society and Leisure, 39(2), 195-209.

Keller, K. L. (2003). Brand synthesis: The multidimensionality of brand knowledge. Journal of Consumer Research, 29(4), 595-600.

Keller, K. L. (2006). Measuring brand equity. In, R. Grover \& M. Vriens (eds.) The Handbook of Marketing Research (pp. 546-568). Thousand Oaks: SAGE Publications Ltd.

Kitchen, P.J., Kim, I., \& Schultz, D.E. (2008). Integrated marketing communication: Practice leads theory. Journal of Advertising Research, 48(4), 531-546. 
Koll, O., Wallpach, S. V., \& Kreuzer, M. (2010). Multi-method research on consumerbrand associations: comparing free associations, storytelling, and collages. Psychology \& Marketing, 27(6), 584-602.

Konecnik, M., \& Go, F. (2007). Tourism destination brand identity: The case of Slovenia. Journal of Brand Management, 15(3): 177-189.

Kotler, P. (2000). Marketing management: The millennium edition. Marketing Management, 23(6), 188-193

Luxton, S., Reid, M., \& Mavondo, F. (2015). Integrated marketing communication capability and brand performance. Journal of Advertising, 44(1), 37-46.

Lebrun, A.-M., Souchet, L., \& Bouchet, p.(2013). Social representations and brand positioning in the sporting goods market. European Sport Management Quarterly, 13(3), pp.358-379.

Macnamara, J. R. (2005). Media content analysis: its uses, benefits and best practice methodology. Asia Pacific Public Relations Journal, 6(1), 1-34.

Maguire, J., Barnard, S., Butler, K., \& Golding, P. (2008). “Celebrate humanity” or “consumers?”: A critical evaluation of a brand in motion. Social Identities, 14(1), 6376.

Matthiesen, I., \& Phau, I. (2005). The 'HUGO BOSS' connection: Achieving global brand consistency across countries. Journal of Brand Management, 12(5), 325-338.

Meliou, E. \& Maroudas, L. (2010). Understanding tourism development: A representational approach. Tourismos: An International Multidisciplinary Journal of Tourism, 5(2), 115-127.

Milton-Smith, J. (2002). Ethics, the Olympics and the search for global values. Journal of Business Ethics, 35, 131-142. 
Muniz, A. M., Jr., \& O'Guinn, T. C. (2001). Brand community. Journal of Consumer Research, 27(4), 412-432.

Nandan, S. (2005). An exploration of the brand identity-brand image linkage: A communications perspective. Journal of Brand Management, 12(4), 264-278.

Ouwersloot, H., \& Odekerken-Schröder, G. (2008). Who's who in brand communitiesand why?. European Journal of Marketing, 42(5/6), 571-585.

Pongsakornrungsilp, S., \& Schroeder, J. E. (2011). Understanding value co-creation in a co-consuming brand community. Marketing Theory, 11(3), 303-324.

Prahalad, C. K., \& Ramaswamy, V. (2004). Co-creation experiences: The next practice in value creation. Journal of Interactive Marketing, 18(3), 5-14.

Rafiq, M., \& Ahmed, P.K. (2000). Advances in the internal marketing concept: definition, synthesis and extension. Journal of Services Marketing, 14(6) 449-462.

Reid, M. (2002). Building strong brands through the management of integrated marketing communications. International Journal of Wine Marketing, 14(3), 37-52.

Reid, M. (2003). IMC-performance relationship: further insight and evidence from the Australian marketplace. International Journal of Advertising, 22(2), 227-248.

Schultz, M., \& de Chernatony, L. (2002). The challenge of corporate branding. Corporate Reputation Review, 5(2-3), 105-112.

Séguin, B., \& O'Reilly, N.J. (2008). The Olympic brand, ambush marketing and clutter. International Journal of Sport Management and Marketing, 4(1), 62-84.

Séguin, B. Richelieu, A., \& O’Reilly, N. (2008). Leveraging the Olympic brand through the reconciliation of corporate consumers' brand perceptions. International Journal of Sport Management and Marketing, 3(1/2), 3-22. 
Spears, N., Brown, T. J., \& Dacin, p.A. (2006). Assessing the corporate brand: The unique corporate association valence (UCAV) approach. Journal of Brand Management, 14(1/2), 5-19.

Srivastava, R. K. (2011). Understanding brand identity confusion. Marketing Intelligence \& Planning, 29(4), 340-352.

UK Sport (2013). Annual Reports and Accounts 2012/13. London: The Stationery Office.

Vallaster, C., \& von Wallpach, S. (2013). An online discursive inquiry into the social dynamics of multi-stakeholder brand meaning co-creation. Journal of Business Research, 66(9), 1505-1515. 